\title{
Undernutrition Under Attention: The Changing Approach of the UK Department for International Development to Nutrition
}

\author{
Jenny Amery and Anne Philpott*
}

\begin{abstract}
DFID is paying attention to undernutrition. This is due to the global lack of progress on the nutrition indicator in Millennium Development Goal 1, the urgency of the situation created by the food price spike of 2008-09 and an increasing understanding within DFID about our potential added value. This article outlines the changing response within DFID globally and in India and reflects on the triggers for the changes and how the changes can be sustained.
\end{abstract}

DFID has faced criticism for lacking a specific nutrition strategy ${ }^{1}$ as reflected in the low profile nutrition has had in official communications. ${ }^{2}$ One report (Sumner et al. 2007) concluded that nutrition is not a visible priority within DFID for a number of reasons, including: the challenge of attribution of indirect interventions (such as social protection and agriculture) on nutrition status, the lack of a 'nutrition sector' leaving the topic to fall between the cracks of other sectors, and the complex nature of direct nutrition interventions with their heavy reliance on behaviour change and cross-sector coordination.

\section{DFID's comparative advantage and potential added value in nutrition \\ DFID's lack of a vertical response to undernutrition is not surprising - this does not play to its strengths of governance, poverty reduction and intersectoral thinking and action. However, these key strengths are potentially very relevant to improving nutritional status.}

Undernutrition results from a series of underlying and interrelated factors, including access to food, care, sanitation, clean water and health services. Poverty is a key underlying determinant of undernutrition, as are gender inequality and social exclusion. Effective responses include empowering women, delivering essential services through health systems, improving food security and efficiency of food markets, provision of social protection, increasing access to water and sanitation, and responding to humanitarian emergencies.

DFID is substantively engaged in policy and programmes in all of these areas, delivered through strong country presence, in many of the high burden countries. At the policy level, DFID could play an important role in 'joining up' disparate policy debates to support longer term, comprehensive approaches to tackling undernutrition, which at their core address vulnerability and chronic poverty. A persistently high or increasing level of chronic undernutrition in children in the face of economic growth is one of the most visible indicators of failed governance - and the case for this could be made more often by DFID.

\section{Why is nutrition so low on the development agenda? What can we learn from AIDS advocacy? Undernutrition and AIDS lead to comparable numbers of deaths and Disability Adjusted Life Years (DALYs) lost per year; however worldwide, total basic nutrition services investments are one-fifth of those to food aid and 19 times less}


Table 1 Factors which may have affected recent policy profiles of HIV/AIDS and undernutrition

DFID position paper due 2009

High income country citizens or elites in low income countries not personally affected by undernutrition

Very few UK lobby groups or specific nutrition advocacy NGOs - little discussion in policy, forums or media

Although spend may be high on indirect nutrition programming, this is hard to quantify and impact data are rare
Two strategies 'Taking Action on AIDS' 2004 and 2008

Elites and high income country citizens infected and affected by HIV/AIDS, or feel vulnerable to HIV infection

Large vocal lobby under umbrella of UK AIDS consortia; constant discussion in media, policy fora and large numbers of parliamentary questions

Donors (including DFID in the past) have spending targets for AIDS programmes than donor assistance for HIV/AIDS. In order to understand the lower policy profile of nutrition, it may be useful to explore analogies with AIDS programming.

Are the successes of advocacy in the AIDS field a model for other development issues? Table 1 highlights some suggested different factors that may have affected the recent trajectories each has had on the DFID and international development stage.

It is clear that one of the key differences is the strong UK lobby for AIDS issues. But what is it that can make elites interested in issues of the poor?

Undernutrition only became an issue of concern in the UK after British army defeats in the second Boer War (1899-1902). This led to national attention to the fitness of the UK army under the politics of 'national efficiency' (Searle 2003; Webb 1908). Arguments were made by proponents of national efficiency that the empire could not be defended if the raw material of the UK were hollow-chested, weak citizens incapable of being enlisted. ${ }^{3}$ However, the UK only developed its first nutrition programme in 1936 after reports revealed an appalling state of malnutrition among the UK population, affecting rich and poor, in the context of conscription and political concerns about the health status of military personnel (Bryce et al. 2008).

Similar analyses in the context of international development have concluded that elites tend to place higher priority on issues such as communicable diseases, to which they are more directly vulnerable. Charles Booth managed to gain the empathy of British elites in Victorian Britain and re-shape the perception of poor people as deserving of support - does this have relevance for how the nutrition agenda could be shaped by appealing to issues of commonality and identity with elites in low income countries and UK voters (Hossain et al. 1999)?

\section{How is DFID's attitude to nutrition changing?}

Analysing the policy cycle and applying it to undernutrition within the current policy environment, one can see opportunities for raising the profile of nutrition (Box 1).

DFID's reputation in building and leading coalition processes, is seen by outsiders as a potential contribution to the fragmented and often dysfunctional international nutrition architecture (Morris et al. 2008). DFID has long been a champion of indirect interventions, crosssectoral working and evidence enhancement for the indirect determinants of the global burden of poverty. Additionally, there is huge overlap between the 20 countries of the world that have 80 per cent of the global burden and the countries where DFID has programmes.

DFID launched a draft nutrition action plan for consultation in November 2008. A public position on nutrition will follow, and will describe how we will contribute to improvement of nutrition globally. It will highlight actions to strengthen DFID's own capacity. It will commit to greater efforts to tackle nutrition in high burden countries through multi-sector approaches in collaboration with key partners and aligned with country processes. It will promote analysis of vulnerability and its impact on nutrition, support the research agenda, build nutrition capacity for 
Policy cycle literature stresses three inter-dependent variables: context, messages and connectors. Applying these variables to nutrition, we find that:

Context (which policy windows are currently open?): The global rise in food prices provides context and has led many development agencies (not just DFID) to reassess their positions on nutrition. Climate change will increasingly do the same.

- Messages (are there a strong set of problem and solution messages?): There is broad agreement that the recent Lancet Nutrition Series (2008) brings an important new body of evidence for the enormous burden and consequences of maternal and child undernutrition that is inhibiting global development. The Series also provides important new evidence for the benefit of a set of specific nutrition interventions. These are targeted at pregnant women and during the first two years of life

- Connectors (are there people, organisations and institutions that can play a championing role?): The major fault line, it could be argued, is the lack of nutrition connectors - or unhealthy competition between potential connectors - to the detriment of coordinated action. This applies equally to national partners as it does to the international architecture.

Source Taken from analysis in the IDS Save 2007 report and the DFID 2008 draft action plan.

effective policy objectives and broad-based partnerships, including private sector and civil society engagement.

\section{A country case study: DFID India and nutrition - what made the difference?}

DFID in India started to recognise the importance of undernutrition and started taking action before the new action plan was created. Box 2 outlines some of the key activities to which DFID India is contributing.

Key triggers for enhancing DFID India work were the stagnating national underweight rate in the presence of rapid economic growth and the extremely high and persistent underweight rates in the poorer states where DFID India works.

Other prompts for more action on undernutrition by DFID in India include the publication of the National Family Health Survey in October 2007, showing a stagnating rate of reduction in underweight rates for under fives. A year later in October 2008, the first Indian State Hunger Index shows in stark terms how DFID focal states fare extremely badly on a global ranking. For example Madhya Pradesh has the worst undernutrition rates in India and on a global scale, ranks between Chad and Ethiopia (von Grebmer et al. 2008).
DFID worked with West Bengal State to develop a state nutrition policy as part of its initial state sector support, and has gone on to work across health and women and child development departments in Orissa, Andrah Pradesh and Madhya Pradesh to support cross-sectoral work on nutrition, and has made significant financial commitments to this work.

In November 2007, DFID India included an annex on nutrition for the Country Business Plan, illustrating the importance of the topic in planning future programming. DFID Ministers visiting India were struck by the comparison of India's poorer states with sub Saharan Africa ${ }^{4}$ and last November, the Secretary of State, Douglas Alexander, launched the DFID draft action plan for consultation at a jointly hosted nutrition event in Delhi. This event was instigated by DFID and brought together UNICEF, USAID, the World Bank and the Government of India to highlight the need for more attention to nutrition security in India.

In summary, DFID India took action as a combination of: internal nutrition champions, shocking statistics in the states where we work and the visibility of underweight children in programmes we supported; high level political 
- Health and nutrition programmes - DFID's focus States constitute 32.5 per cent of India's total population and Madhya Pradesh, Bihar and Orissa have the highest child mortality rates in India. All DFID's four established state health and nutrition programmes have reduction in underweight rates and infant mortality as key objectives, and work with key ministries including Health, Women and Child Development and in Bihar Water and Sanitation.

- Reproductive and Child Health-II - this central Government programme will have a direct or indirect impact on nutrition indicators - including expanded access to antenatal care, nutrition advice during pregnancy, promoting early and exclusive breastfeeding, early child feeding and micronutrient supplementation.

- Rural livelihoods programmes - improving access to food, crop and livestock production, employment, microenterprises, and food for work initiatives.

- UNICEF - support to ensure best practice and intensive pilot activities to influence national/state policy in eight key states.

- Support to Government of India Education programmes - girls' education and women's empowerment to improve intergenerational nutritional outcomes.

- Technical support for the Government's Integrated Child Development Scheme (GoI's major nutrition programme), including focus on social exclusion and impact evaluation.

interest and a recognition by DFID and our partners that we could and should do more.

\section{Conclusion - focus on nutrition security in the} global economic downturn

DFID globally is placing a higher priority on nutrition security. This is in part a response to the economic downturn, which could leave a generation of children suffering long-term damage as a consequence of undernutrition - a terrible and preventable legacy of the global crisis. DFID India, amongst other countries, is

\section{Notes}

* The views expressed in this article do not necessarily represent those of DFID.

1 The Parliamentary Committee on Development Committee stated in February 2008 that 'Malnutrition is responsible for one third of child deaths. Yet nutrition is underfunded and under-emphasised by the international community and the UN system. We are shocked that DFID lacks both a specific nutrition policy and measurable targets for assessing progress in reducing working closely with DFID HQ to strengthen efforts to address undernutrition.

This is an opportunity for the international nutrition community to re-think advocacy and action for nutrition. To learn from other examples of success - either current or historical - to alert people in rich countries and policy makers in low income countries to the undernutrition crisis. The current economic downturn is a huge challenge and an opportunity.

malnutrition. This must change'. House of Commons International Development Committee, The World Food Programme and Global Food Security, Tenth Report of Session 2007-08.

2 This criticism follows on from a report published by IDS and Save the Children UK (Sumner et al. 2007), which stated that while DFID sees nutrition improvement as critical to MDG achievement, it is - at best - given a medium priority within the agency. Eleven per cent of the world's global burden of disease is 
caused by undernutrition and yet nutrition was not mentioned in any of the official DFID G8 communications in 2005/06 and not once in the major published speeches given by senior DFID officials between 2005 and 2007.

3 Including Churchill's interest in a national wellbeing minimum 'below which the individual, whether he likes it or not, (could

\section{References}

Bryce, J.; Coitinho, D.; Darnton-Hill, I.; Pelletier, D. and Pinstrup-Andersen, P.; Maternal and Child Undernutrition Study Group (2008) 'Maternal and Child Undernutrition: Effective Action at National Level', Lancet 371.9611: 510-26

Hossain, N. and Moore, M. (1999) Elites, Poverty and Development, background paper for the World Development Report 2000/1 on Poverty, Brighton: IDS

Morris, S.S.; Cogill, B.; Uauy, R.; Maternal and Child Undernutrition Study Group (2008) 'Effective International Action Against Undernutrition: Why Has it Proven So Difficult and What can be Done to Accelerate Progress?', Lancet 371.9612: 608-21

Searle, G.R. (2003) 'The Politics of National Efficiency and of War, 1900-1918', in A not) in the interests of the wellbeing of the whole, ever be allowed to fall'.

4 DFID PUSS Shriti Vadera spoke to the Indian press about undernutrition on her DFID visit to India, when she said: '...But also noticeable are the malnutrition levels'. Hindustan Times, New Delhi, 4 November 2007.

Companion to Early 20th Century Britain, Oxford: Blackwell: 56-70

Sumner, A.; Lindstrom, J. and Haddad, L. (2007)

Greater DFID and EC Leadership on Chronic Malnutrition: Opportunities and Constraints, commissioned by Save the Children Fund UK Brighton: IDS

Lancet (2008) Series on Maternal and Child Undernutrition 371.9612, 16 February

von Grebmer, K.; Fritschel, H.; Nestorova, B.;

Olofinbiyi, T.; Pandya-Lorch, R. and Yohannes, Y. (2008) The Challenge of Hunger 2008: Global Hunger Index, Welthungerhilfe, International Food Policy Research Institute (IFPRI), and Concern Worldwide, www.ifpri.org/pubs/cp/ ghi08.asp (accessed 16 May 2009)

Webb, S. (1908) 'The Necessary Basis of Society', Contemporary Review 93: 665-7 